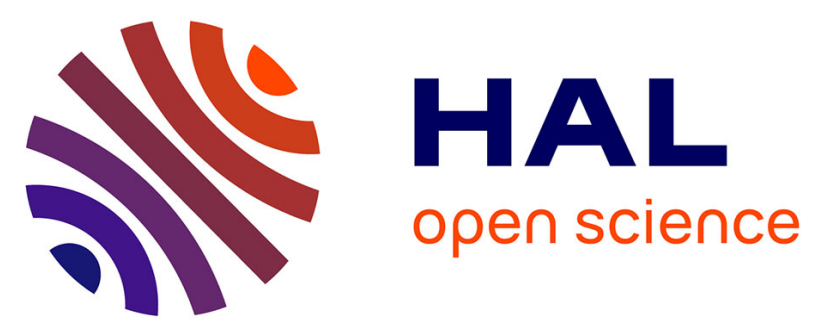

\title{
Effectiveness of heart rate control on hemodynamics in critically ill patients with atrial tachyarrhythmias managed by amiodarone
}

Joe-Elie Salem, Pauline Dureau, Christian Funck-Brentano, Jean-Sébastien Hulot, Maria Aissaoui, Nadia Aissaoui, Saik Urien, Christophe Faisy

\section{To cite this version:}

Joe-Elie Salem, Pauline Dureau, Christian Funck-Brentano, Jean-Sébastien Hulot, Maria Aissaoui, et al.. Effectiveness of heart rate control on hemodynamics in critically ill patients with atrial tachyarrhythmias managed by amiodarone. Pharmacological Research, 2017, 122, pp.118 - 126. 10.1016/j.phrs.2017.06.004 . hal-01540356

\section{HAL Id: hal-01540356 https://hal.sorbonne-universite.fr/hal-01540356}

Submitted on 16 Jun 2017

HAL is a multi-disciplinary open access archive for the deposit and dissemination of scientific research documents, whether they are published or not. The documents may come from teaching and research institutions in France or abroad, or from public or private research centers.
L'archive ouverte pluridisciplinaire HAL, est destinée au dépôt et à la diffusion de documents scientifiques de niveau recherche, publiés ou non, émanant des établissements d'enseignement et de recherche français ou étrangers, des laboratoires publics ou privés. 


\section{Effectiveness of heart rate control on hemodynamics in critically ill patients with atrial tachyarrhythmias managed by amiodarone}

Running title: AT, heart rate, amiodarone and hemodynamics in ICU

Joe-Elie Salem, MD-PhD †\#, Pauline Dureau, MD †, Christian Funck-Brentano, MDPhD †, Jean-Sébastien Hulot MD-PhD †, Maria El-Aissaoui, MD ‡, Nadia Aissaoui, MD-PhD $\ddagger$, Saik Urien*, MD-PhD ॥, Christophe Faisy* MD-PhD †॥

*Saik Urien and Christophe Faisy contributed equally as last authors

† AP-HP, Pitié-Salpêtrière Hospital, Department of Pharmacology and CIC-1421, F-75013 Paris, France; INSERM, CIC-1421 and UMR ICAN 1166, F-75013 Paris, France; Sorbonne Universités, UPMC Univ Paris 06, Faculty of Medicine, Department of Pharmacology and UMR ICAN 1166, F-75013 Paris, France; Institute of Cardiometabolism and Nutrition (ICAN)

‡ Critical Care Unit, Hôpital Européen Georges Pompidou, Assistance Publique - Hôpitaux de Paris, University Paris Descartes Sorbonne Paris Cité, Paris, France.

II CIC-1419 INSERM, EAU-08 University Paris Descartes Sorbonne Paris Cité, Paris, France. \# Cardiology - Rythmology Unit, Pitié-Salpêtrière Hospital, Assistance Publique - Hôpitaux de Paris, F-75013 Paris, France

Request for reprints and correspondence: Joe-Elie Salem, joeelie.salem@gmail.com, Centre d'Investigation Clinique Paris-Est, Hôpital La Pitié-Salpêtrière, 47-83 Bld de l'hôpital, 75651 


\section{Graphical abstract}

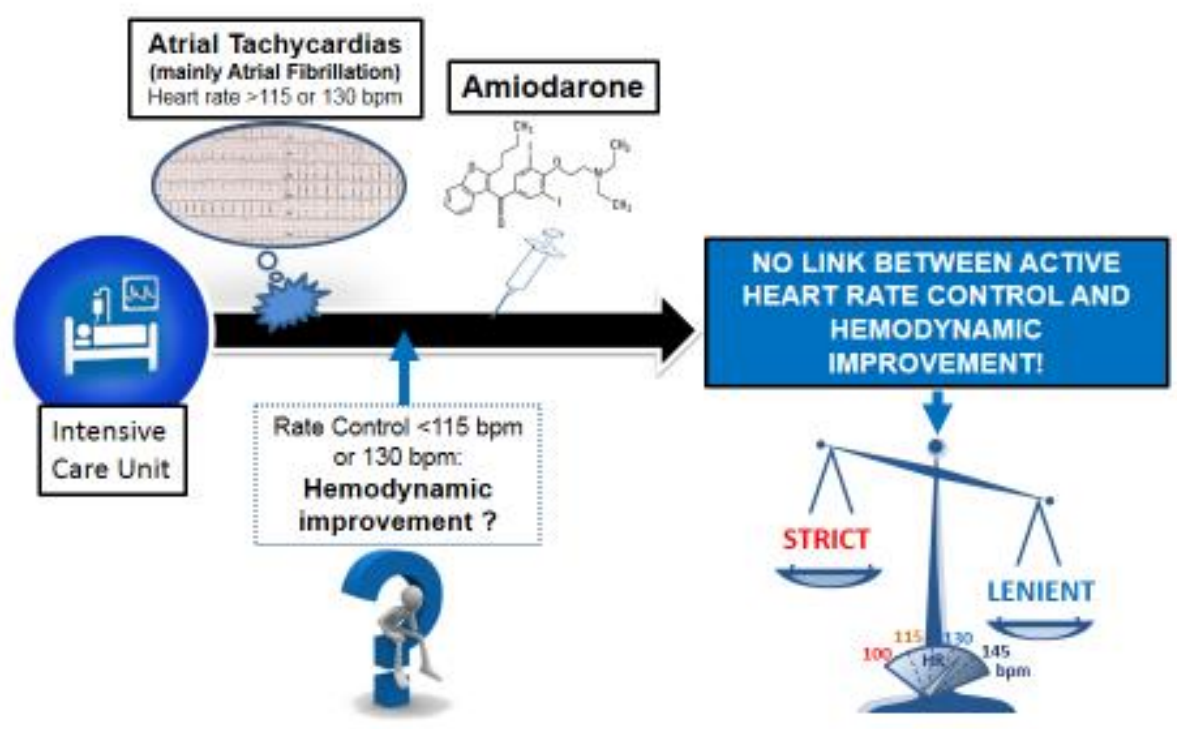

\section{ABSTRACT}

Atrial tachyarrhythmias (AT) are common in intensive care unit (ICU) patients and might contribute to hemodynamic instability if heart rate $(\mathrm{HR})$ is persistently too rapid. We aimed to assess if HR control below 115 or 130 bpm with amiodarone improves hemodynamics in ICU patients with AT.

This observational study included 73 ICU patients with disabling AT receiving amiodarone for HR control. A total of 525 changes (mainly within 4-8 h) in mean arterial pressure (MAP) and 167 changes in plasma lactate in response to $\mathrm{HR}$ variations above 115 or 130 bpm were analyzed. Epinephrine, sedative drugs, fluid loading, use of diuretics, continuous renal replacement therapy and amiodarone dosing were among covariables assessed.

Univariable analysis showed that HR variations above $115 \mathrm{bpm}$ were poorly correlated to change in MAP $(r=0.11, p<0.01)$. Multivariable analysis showed that changes in MAP were still positively associated to $\mathrm{HR}$ variation $(p<0.05)$ and to initiation or termination of epinephrine $(p<0.05)$ or sedatives infusions $(p<0.05)$. Changes in plasma lactate did not correlate to HR variations above $115 \mathrm{bpm}$. When considering $130 \mathrm{bpm}$ as a threshold, HR variations were not associated to changes in MAP or to changes in 
plasma lactate. Amiodarone dose was associated to HR decrease but not to MAP or plasma lactate increase.

In ICU patients with AT, strict HR control below $115 \mathrm{bpm}$ or $130 \mathrm{bpm}$ with amiodarone does not improve hemodynamics. A prospective randomized trial assessing strict versus lenient $\mathrm{HR}$ control in this setting is needed.

\section{ABBREVIATIONS LIST}

AT: atrial tachyarrhythmias

bpm: beats per minute

CRRT: continuous renal replacement therapy

ECG: electrocardiogram

ECV: electrical cardioversion

HR: heart rate

ICU: intensive care unit

IV: intravenous

MAP: mean arterial pressure

mg: milligram

Key words: amiodarone, atrial tachyarrhythmia, pharmacology, shock, heart rate.

\section{INTRODUCTION}

Atrial tachyarrhythmias (AT) (atrial fibrillation, atrial flutter, atrial tachycardia or atrioventricular arrhythmias) are highly prevalent and are associated with a poor outcome in critically ill patients admitted in intensive care units (ICU) ${ }^{[1,2]}$. AT are often associated with a ventricular heart rate (HR) above 120-130 beats per minute (bpm) which contributes to baroreflex impairment, ${ }^{[3]}$ diastolic dysfunction and may lead to cardiac systolic dysfunction. Such induced ventricular tachycardiomyopathy is associated with hemodynamic instability and increased morbidity or mortality $[2,4,5]$. In 
severely ill patients with AT, a rate or rhythm control strategy with amiodarone is recommended for the treatment or prevention of ventricular tachycardiomyopathy [6-7]. Attempts to restore sinus rhythm are frequently unsuccessful in the setting of critically ill patients ${ }^{[8-10]}$, particularly when using electrical cardioversion without antiarrhythmic pretreatment. HR control is thus the preferred strategy in this situation ${ }^{[10-12]}$. In nonICU patients, guidelines recommend aiming at a HR control between 90-115 bpm during stress situations ${ }^{[6,7,13]}$. There are no specific guidelines for patients in severely ill condition but it is commonly advocated that reaching a HR below $115 \mathrm{bpm}$ or a maximum of $130 \mathrm{bpm}$ is advisable ${ }^{[6,7,14]}$. Thus, it is unknown whether exceeding these HR cut-offs, even for short periods of time, is associated with alterations of hemodynamics, i.e. fall of mean arterial pressure (MAP) ${ }^{[15,16]}$ or increase of plasma lactate levels ${ }^{[17]}$.

In a former study [18], we modelled the relationship between amiodarone dose and heart rate variation but did not assess the influence of heart rate control on restoration of hemodynamics. The objective of this study was to determine if magnitude of HR variations above 115 or $130 \mathrm{bpm}$ are associated to variations in MAP or plasma lactate. The analyses took into account variables such as paroxysmal vs persistent AT and others confounding factors relevant to ICU patients ${ }^{[19]}$ such as epinephrine treatment, sedative or curare drugs infusion, fluid loading, amiodarone dose, use of diuretics or continuous renal replacement therapy (CRRT).

\section{MATERIAL AND METHODS \\ Patients and Study Design}

This observational, cohort study was performed from January 2007 to April 2012 in the 18-bed medical ICU of a tertiary teaching hospital. In accordance with the French legislation on observational studies, approval by an investigational review board was not required. The use of confidential electronically processed patient data was approved by the French National for Data Protection Commission (Commission Nationale de l'Informatique et des Libertés; reference: 1922081). Data were extracted from the files of 73 consecutive critically ill patients who had received at least one dose of amiodarone (Mylan laboratory, Saint-Priest, FRANCE) to treat a disabling AT during their ICU stay (Figure 1). HR and MAP data (average of at least 3 measures over 5 minutes) were collected at the time of the first amiodarone administration in intensive 
care unit (ICU) and then 4 to 6 times daily over 6 days or until death or ICU discharge. MAP values were obtained through an arterial catheter attached to a fluid-filled pressure transducer system incorporating a flush system, which continuously infused a solution under pressure to maintain patency of the catheter. An attached transducer senses arterial pressure and converted the pressure signal to a waveform on a Phillips ${ }^{\circledR}$ bedside monitor. The waveform reflected pressure generated by the left ventricle during systole. The monitor also displayed automatically numerical MAP values. HR were also displayed on the monitor and computed by automatic QRS detection from continuous acquisition of a digital electrocardiographic signal. Plasma lactate levels were drawn at the discretion of the treating physician without any predefined protocol and were determined by an arterial blood gas analyser (ABL 825, Radiometer, Copenhagen, Denmark). Details concerning modalities of amiodarone administration in this cohort and estimation of pharmacodynamically active amiodarone dose at each time point were estimated as previously described in detail [18]. Briefly, amiodarone could be administered either intravenously (IV) as amiodarone hydrochloride $150 \mathrm{mg} / 3 \mathrm{~mL}$ or orally as $200 \mathrm{mg}$ tablet(s). Route, frequency of administrations and doses were left at the discretion of the treating physician. Other treatments were administered according to standard guidelines ${ }^{[14]}$.

\section{Variables collection}

The following covariables were recorded the time of first HR and MAP collection: age, gender, body weight, severity score at ICU admission, diabetes, hypertension, AT history, bilirubinemia, previous amiodarone treatment and type of AT. Paroxysmal and persistent AT were defined as an arrhythmia occurring less or more than one week before the first amiodarone administration in ICU, respectively. Prior chronic and subacute amiodarone treatment before ICU were defined as continuous amiodarone treatment since more than one month or a cumulated amiodarone dose of less than 4 grams in the last month, respectively.

Time-dependent covariables potentially interacting with hemodynamic conditions were recorded at the time of each HR, MAP, and plasma lactate collection. These were: body temperature, arterial $\mathrm{pH}$ or $\mathrm{PaO}_{2}$, hemoglobin, electrical cardioversion, fluid loading, pharmacodynamically active amiodarone dose or use of other antiarrhythmic drugs, loop diuretics, catecholamine, curare or sedative drugs and need for CRRT. Fluid loading was defined as administration of more than $0.5 \mathrm{~L}$ of saline solution in 30 
min. Electrocardiographic acquisition allowing for accurate evaluation of type of rhythm was left at the discretion of the treating physician.

As previously reported ${ }^{[18]}$, pharmacodynamically active amiodarone dose for each subject was determined at the time of each HR, MAP, and plasma lactate collection. In brief, amiodarone pharmacokinetics was ascribed to a virtual compartment model including zero or first order input rates. This virtual compartment, $A(t)$, represents the biophase in which amiodarone amount is in equilibrium with the observed effect on heart rate. Pharmacodynamic half-life (KDE) was determined to be 3.33 days. $G(t)$ represents the amiodarone amount in the gut at a given time and $\mathrm{ka}$, the first-order absorption rate, which was fixed to 8 . Amiodarone bioavailability $(F)$ was fixed to 0.33 .

$$
\begin{aligned}
& d A(t) / d t=\text { input }-K D E \times A(t) \\
& \text { input }=k a \times G(t) \times F \text { if administered orally }
\end{aligned}
$$

\section{Statistics}

Results are expressed as numbers (\%), means \pm standard deviation, or medians (interquartile ranges) as appropriate. Normality was assessed by the D'AgostinoPearson omnibus normality test. Comparison of continuous variables were analyzed by Mann-Whitney test for non-paired and non-parametric distribution. Comparison of categorical variables were analyzed by Chi-2 test. The correlation $(r)$ between linear variables was assessed by calculating Pearson's for parametric distribution or Spearman's coefficient for non-parametric distribution (Prism 6, GraphPad software $\circledast$, San Diego, USA). Of note, we had a power of at least $80 \%$ to detect a modest correlation ( $r>0.27$ ) between variation of $\mathrm{HR}$ and variation of hemodynamic surrogates (MAP and plasma lactate). Multivariable analysis was performed by using linear mixed effect modeling that takes into account repeated measures (package nIme, Linear and Nonlinear Mixed Effects Models, R statistical software, https://www.r-project.org). The general equation is:

$$
Y=\text { intercept }+\beta_{1}{ }^{*} X_{1}+\beta_{2}{ }^{*} X_{2}+\ldots+\beta_{n}{ }^{*} X_{n}+\eta
$$

Where $Y$ is the dependent variable, $X_{1}, \ldots, X_{n}$ and $\beta_{1}, \ldots, \beta_{n}$ stand for the explanatory variables and the corresponding regression coefficient respectively. $\eta$ denotes the random effect (it models the differences between the patients). Estimation of pharmacodynamically active amiodarone doses ${ }^{[18]}$ at each time-point were derived using $\mathrm{R}$ statistical software (https://www.r-project.org). Statistical significance was accepted for $P<.05$. 


\section{RESULTS}

\section{Study Population and Time-Dependent Observations}

Seventy three consecutive patients admitted to ICU received at least one amiodarone dose for AT HR control and were eligible for analysis [Figures 1-2]. Of these 73 patients, 68 and 62 patients had at least one HR above $115 \mathrm{bpm}$ or $130 \mathrm{bpm}$, respectively, thereby allowing for analysis of association between concomitant variations of MAP $(\triangle M A P)$ and HR $(\triangle H R)$, above $115 \mathrm{bpm}(n=525)$ or $130 \mathrm{bpm}(n=$ 313) (Figure 1). Most of these variations were evaluated during a period of time of 4 to 8 hours (Table 1). Fifty three and 45 patients had at least one HR above $115 \mathrm{bpm}$ and $130 \mathrm{bpm}$ and at least two plasma lactate levels available, respectively, allowing for analysis of association between concomitant variations of plasma lactate ( $\Delta$ lactate) and HR $(\Delta H R)$, above $115 \mathrm{bpm}(n=167)$ or $130 \mathrm{bpm}(n=106)$ (Figures 1-2). Most of these variations were evaluated during a period of time of 6 to $24 \mathrm{~h}$ (Table 1). Patients included were severely ill. They were mainly admitted for cardiogenic shock or sepsis, had cardiovascular comorbidities and initially received amiodarone during their ICU stay for heart rate control either IV or mostly orally (Table 2). Dobutamine (11\%) or epinephrine (61\%) were the only IV catecholamine used. CRRT (25\%), loop diuretics $(49 \%)$, sedative drugs $(60 \%)$ and fluid loading $(70 \%)$ were frequently used. The main clinical, demographic and biological patient's characteristics and other treatments that could interfere with hemodynamic status are summarized in Table 2. Forty eight patients $(66 \%)$ had paroxysmal AT and 25 patients $(34 \%)$ had persistent AT. Despite a higher proportion of uncontrolled HR collected above $130 \mathrm{bpm}$ in patients with paroxysmal than persistent AT ( $25 \%$ vs $19 \%, p=0.01$ ), proportion of MAP below 65 mmHg was not different ( $20 \%$ vs $20 \%, p=n s)$ and proportion of plasma lactate $>2.2 \mathrm{mmol} / \mathrm{L}$ was lower in patients with paroxysmal AT as compared to patients with persistent AT $(23 \%$ vs $43 \%, \mathrm{p}<0.0001)$ [Figure 3]. Variations in estimated pharmacodynamically active dose of amiodarone were correlated to variations in $\mathrm{HR}$ $(r=0.31, P<.0001)$ [Figure 4].

\section{Heart rate variation and hemodynamics}

Univariable analysis showed that HR variations above $115 \mathrm{bpm}$ were poorly associated to changes in MAP $(r=0.11 \pm 0.04, P .02$; Figure 5A). The results of multivariable analysis integrated catecholamine, curare or sedative drugs infusion, fluid loading, persistent versus paroxysmal AT, use of diuretics or CRRT and estimated 
pharmacodynamically active amiodarone dose or its variation. It showed that variations in MAP were associated to initiation or termination/weaning of epinephrine ( $\beta=$ $14.5 \pm 6.5$ for initiation vs. termination/weaning, $P=0.02 ; \beta=10.6 \pm 4.9$ for no change vs. termination/weaning, $P=0.03)$ and sedative drugs $(\beta=18.3 \pm 8.4$ for termination vs. initiation, $P=0.03$ ). Variation in HR was still positively associated to variation in MAP ( $\beta$ $=0.06 \pm 0.03, P=0.03$ ) but contribution of amiodarone pharmacodynamically active amount or other covariables were insignificant to explain variation in MAP.

When considering $130 \mathrm{bpm}$ as threshold, HR variations were not associated to changes in MAP in univariable analysis (Figure 5B). Multivariable analysis showed that variations in MAP were also associated to initiation or termination/weaning of epinephrine ( $\beta=27 \pm 9.4$ for initiation vs. termination/weaning, $P=0.005 ; \beta=16 \pm 7.8$ for no change vs. termination/weaning, $P=0.04)$ and sedative drugs $(\beta=27.2 \pm 11.9$ for termination vs. initiation, $\mathrm{P}=0.02$ ). Variation of amiodarone pharmacodynamically active amount was also positively associated with variation in $\operatorname{MAP}(\beta=0.01 \pm 0.005$, $P=0.03$ ). Other co-variables, including variation in $H R$, were not associated to variation in MAP.

We did not test other HR threshold because too few HR were available above 150 or $200 \mathrm{bpm}$ in a limited number of patients (Table 1). Restoration of sinus rhythm could not be examined in our multivariable analysis because we had too few accurate characterizations of rhythm type evaluated by electrocardiogram (Table 1). However, univariable analysis showed that changes in plasma lactate were not associated to HR variations above $115 \mathrm{bpm}$ (Figure $\mathbf{5 C}$ ) but tended to be associated to restoration of sinus rhythm ( $-0.3 \mathrm{vs} 0 \mathrm{mmol} / \mathrm{L}, P=0.06$, Figure $5 \mathrm{E}$ ). Univariable analysis showed that changes in plasma lactate were not associated to HR variations above $130 \mathrm{bpm}$ (ns; Figure 5D) or to restoration of sinus rhythm (-0.3 vs $0 \mathrm{mmol} / \mathrm{L}, P=0.12$, Figure $5 \mathrm{~F}$ ).

\section{DISCUSSION}

The present study indicates that, in critically ill patients with AT, acute HR increases above $115 \mathrm{bpm}$ or $130 \mathrm{bpm}$ are not associated with acute deterioration of hemodynamic surrogates, i.e. increase of plasma lactate and decreases of MAP. In this setting, use of epinephrine or absence of sedative drugs are major determinants of MAP increase while restoration of sinus rhythm might improve plasma lactate levels.

Patients with paroxysmal AT had a higher proportion of HR above 130bpm than patients with persistent AT. Thus, patients with paroxysmal AT had a lower proportion of plasma lactate above $2.2 \mathrm{mmol} / \mathrm{L}$, as compared to patients with 
persistent AT. This finding further enhance absence of negative association between increased HR and deleterious hemodynamic response. We also found that amiodarone slows HR without altering hemodynamic markers.

\section{Avoiding Ventricular Tachycardiomyopathy}

AT, if persistent and rapid, can lead to tachycardia-induced cardiomyopathy with heart failure ${ }^{[3]}$. This condition is reversible, either by HR or rhythm control. Amiodarone is the gold standard medication to prevent or cure this condition in critically ill patients with AT, particularly if kidney failure, ionic disturbances and heart failure are present $[6,7]$. Whether brief episodes of rapid AT or sinus rhythm exceeding thresholds of 115 or $130 \mathrm{bpm}$ carry a significant risk of tachycardia-induced cardiomyopathy in ICU patients remains unknown. Also, the best target HR and molecule to use are still unknown ${ }^{[5,6,20,21] .}$

\section{Amiodarone and Hemodynamics}

In this observational study, amiodarone was mainly administered by oral route. In the past, the IV route of administration was known to be associated with transient hypotension and hemodynamic impairment ${ }^{[22-24]}$. However, the aqueous form of IV amiodarone used in our patients was not expected to be associated with this specific side effect [25]. Our results did not show any negative association between the estimated pharmacodynamically active amiodarone dose in organism and surrogates of global hemodynamic status. These data further support the safety of newer IV amiodarone hydrochloride formulation. Beta-blockers and verapamil were exceptionally used in this study because of their negative inotropic effects ${ }^{[20]}$. Digoxin was also very rarely used because of its poor efficacy to rapidly slow HR, important dependency to renal clearance, and significant interaction with amiodarone or ionic disorder that may lead to adverse events ${ }^{[6,7]}$.

\section{Epinephrine, Sedative Drugs and Hemodynamics}

In our study, we found that epinephrine use was associated with an increase of MAP while sedative drugs had an opposite effect. Epinephrine has alpha-1 and beta adrenergic agonist properties, determining its inotropic and vasopressive effects. In contrast, dobutamine, an inodilator selective beta adrenergic agonist ${ }^{[25]}$, was not found to be a major determinant of MAP variation. This might be explained by vasodilatation compensating its inotropic effect. Sedative drugs used in these patients were systematically relying on an association of a morphine derivate (sufentanil) with benzodiazepine (midazolam), which association is well known to decrease MAP [26]. 


\section{Limitations}

In our multivariable analysis, there was no significant influence of fluid loading. Its effect on MAP is expected to occur in the short term and not necessarily after a few hours of administration. Since the delay between two MAP collections was of a few hours, the effect of fluid therapy on MAP was possibly not sustained enough to be detected. Neither furosemide administration nor CRRT were identified as significant covariables. We hypothesize that patients treated with these depletive strategies had high pre-therapeutic filling pressures and did not experience hypovolemia and reactional MAP decrease.

In this observational study in critically ill patients, other covariables of interest such as left ventricular ejection fraction, plasma catecholamine levels, oxidative stress measurement, baroreflex and autonomic function analysis, which may influence hemodynamic response were not taken into consideration. However, this study shows for the first time the lack of effectiveness of aggressive acute heart rate control strategy to restore hemodynamics in critically ill patients.

Plasma levels of amiodarone and its metabolite $\mathrm{N}$-desethylamiodarone, were not tested in our analysis because amiodarone therapeutic drug monitoring is not recommended in clinical practice ${ }^{[6,7]}$. It should be emphasized that individual plasma concentrations are poorly predictive of amiodarone pharmacodynamics response ${ }^{[27,28]}$.

\section{Perspectives}

Several studies have evaluated the potential benefit of lenient versus strict heart rate control or rhythm control in the context of persistent AT in non-critically ill patients $[12,13,29]$. These studies did not show any difference in outcome among these strategies. Recently, Gillinov et al. further showed that strategies of rate or rhythm control to treat postoperative atrial fibrillation were not significantly different in terms of numbers of days of hospitalization, complication rates and rates of persistent atrial fibrillation 60 days after onset. ${ }^{[30]}$

Our study is the first to address this issue in critically ill patients. Its findings emphasize the importance of conducting a prospective trial of amiodarone dosing in critically ill patients with mostly "reactional" AT due to severe conditions comparing a lenient versus a strict rate control or even a rhythm control strategy. We recently proposed a tailored amiodarone dosing strategy according to duration of AT (paroxysmal versus persistent) and amiodarone pretreatment or not, which might help achieve a heart rate of $115 \mathrm{bpm}$ more conveniently (less systemic side effects, 
bradycardia and hypotension) than a highly aggressive strategy relying on physician's decisions without any standardized protocol ${ }^{[18]}$. Paroxysmal AT needed lower doses of amiodarone to achieve the same level of rate control, as compared to persistent AT. Furthermore, addition of intravenous magnesium and vascular filling improved amiodarone efficacy to slow HR, as opposed to concomitant use of dobutamine [18].

\section{CONCLUSION}

In critically ill patients with AT, strict heart rate control below 115 bpm or even 130 bpm is not associated with hemodynamic improvement. Our data suggest that lenient heart rate control around $130 \mathrm{bpm}$ might not be deleterious for these patients. A prospective randomized trial assessing strict versus lenient heart rate control or even rhythm control in critically ill patients with AT is needed to further address this issue.

\section{DISCLOSURES}

JES, PD, CFB, MEA, NA, SU, CF declare that they have no conflict of interest.

Conflict of interest: None

\section{ACKNOWLEDGMENTS}

Dr Salem had full access to all of the data in the study and takes responsibility for the integrity of the data and the accuracy of the data analysis. Dr Salem, Dr Aissaoui and Pr Faisy contributed to the conception and design of the study. Dr Salem, Dr ElAissaoui and Dr Dureau contributed to data collection. Dr Salem, Dr Urien, Pr Faisy, Pr Funck-brentano and Pr Hulot contributed to analysis and/or interpretation of the data. Dr Salem, Pr Faisy, and Dr Urien contributed to drafting the manuscript. All authors contributed to revision of the manuscript and accepted the submitted version. We thank Margaux Alazard for help in data collection.

No external funding was used in the preparation of this manuscript. 


\section{REFERENCES}

1. Artucio H, Pereira M. Cardiac arrhythmias in critically ill patients: epidemiologic study. Crit Care Med. 1990;18(12):1383-8.

2. Walkey AJ, Hogarth DK, Lip GY. Optimizing atrial fibrillation management: from ICU and beyond. Chest. 2015;148(4):859-64.

3. Field ME, Wasmund SL, Page RL, Hamdan MH. Restoring Sinus Rhythm Improves Baroreflex Function in Patients With Persistent Atrial Fibrillation. J Am Heart Assoc. 2016; 23(2):5.

4. Nerheim P, Birger-Botkin S, Piracha L, Olshansky B. Heart failure and sudden death in patients with tachycardia-induced cardiomyopathy and recurrent tachycardia. Circulation. 2004;110(3):247-52.

5. Tseng YH, Ko HK, Tseng YC, Lin YH, Kou YR. Atrial Fibrillation on Intensive Care Unit Admission Independently Increases the Risk of Weaning Failure in Non heart Failure Mechanically Ventilated Patients in a Medical Intensive Care Unit: A Retrospective CaseControl Study. Medicine (Baltimore). 2016;95(20):e3744.

6. European Heart Rhythm Association, European Association for Cardio-Thoracic Surgery, Camm AJ, Kirchhof P, Lip GY et al. Guidelines for the management of atrial fibrillation: the Task Force for the Management of Atrial Fibrillation of the European Society of Cardiology (ESC). Eur Heart J. 2010(19);31:2369-429.

7. January CT, Wann LS, Alpert JS. 2014 AHA/ACC/HRS guideline for the management of patients with atrial fibrillation: a report of the American College of Cardiology/American Heart Association Task Force on Practice Guidelines and the Heart Rhythm Society. Circulation. 2014(23);130:2071-104.

8. Arrigo M, Jaeger N, Seifert B, Spahn DR, Bettex D, Rudiger A. Disappointing Success of Electrical Cardioversion for New-Onset Atrial Fibrillation in Cardiosurgical ICU Patients. Crit Care Med. 2015;43(11):2354-9.

9. Mayr A, Knotzer H, Mutz N, Hasibeder W. Atrial tachyarrhythmia after cardiac surgery. Intensive Care Med. 1999;25(2):242-3.

10. Mitrić G, Udy A, Bandeshe $H$, Clement $P$, Boots $R$. Variable use of amiodarone is associated with a greater risk of recurrence of atrial fibrillation in the critically ill. Crit Care. 2016;20(1):90.

11. Delle Karth G, Geppert A, Neunteufl T et al. Amiodarone versus diltiazem for rate control in critically ill patients with atrial tachyarrhythmias. Crit Care Med. 2001; 29(6):1149-53.

12. Carlsson J, Miketic S, Windeler $\mathrm{J}$ et al; STAF Investigators. Randomized trial of ratecontrol versus rhythm-control in persistent atrial fibrillation: the Strategies of Treatment of Atrial Fibrillation (STAF) study. J Am Coll Cardiol. 2003;41(10):1690-6. 
13. Van Gelder IC, Hagens VE, Bosker HA et al; Rate Control versus Electrical Cardioversion for Persistent Atrial Fibrillation Study Group. A comparison of rate control and rhythm control in patients with recurrent persistent atrial fibrillation. N Engl J Med. 2002; 347(23):1834-40.

14. Khoo CW, Lip GY. Acute management of atrial fibrillation. Chest. 2009;135(3):849-59.

15. Rhodes A, Evans LE, Alhazzani W, et al. Surviving Sepsis Campaign: International Guidelines for Management of Sepsis and Septic Shock: 2016. Intensive Care Med. 2017 Jan 18.

16. Thiele H, Ohman EM, Desch S, Eitel I, de Waha S. Management of cardiogenic shock. Eur Heart J. 2015 May 21;36(20):1223-30.

17. Kraut JA, Madias NE. Lactic acidosis. N Engl J Med. 2014;371(24):2309-19.

18. Salem JE, El-Aissaoui M, Alazard M et al. Modeling of Amiodarone Effect on Heart Rate Control in Critically III Patients with Atrial Tachyarrhythmias. Clin Pharmacokinet. 2016 Aug;55(8):991-1002

19. Lafont E, Urien S, Salem JE, Heming N, Faisy C. Modeling for critically ill patients: An introduction for beginners. J Crit Care. 2015;30(6):1287-94.

20. Walkey AJ, Evans SR, Winter MR, Benjamin EJ. Practice Patterns and Outcomes of Treatments for Atrial Fibrillation During Sepsis: A Propensity-Matched Cohort Study. Chest. 2016;149(1):74-83.

21. Patel J. Don't Rush to "Block" Atrial Fibrillation in Sepsis. Chest. 2016;149(5):1348.

22. Schwartz A, Shen E, Morady $F$ et al. Hemodynamic effects of intravenous amiodarone in patients with depressed left ventricular function and recurrent ventricular tachycardia. $A m$ Heart J. 1983;106(4Pt2):848-56.

23. Remme WJ, Kruyssen HA, Look MP et al. Hemodynamic effects and tolerability of intravenous amiodarone in patients with impaired left ventricular function. Am Heart J. 1991; 122(1Pt1):96-103.

24. Souney PF, Cooper WD, Cushing DJ. PM101: intravenous amiodarone formulation changes can improve medication safety. Expert Opin Drug Saf. 2010;9(2):319-33.

25. Salem JE, Aissaoui $N$, Paluszkiewicz $L$ et al. Impact of inodilator drugs on echocardiographic assessments of left ventricular filling pressure in patients with decompensated end-stage heart failure. Crit Care Med. 2014;42(12):2508-17.

26. Crozier TA, Langenbeck M, Müller J, Kietzmann D, Sydow M, Kettler D. Total intravenous anaesthesia with sufentanil-midazolam for major abdominal surgery. Eur $J$ Anaesthesiol. 1994;11(6):449-59.

27. Greenberg ML, Lerman BB, Shipe JR, Kaiser DL, DiMarco JP. Relation between amiodarone and desethylamiodarone plasma concentrations and electrophysiologic effects, efficacy and toxicity. J Am Coll Cardiol. 1987;9(5):1148-55. 
28. Deharo JC, Durand A, Macaluso G, et al. Clinical electrophysiologic effects of a single high oral dose of amiodarone. Fundam Clin Pharmacol. 1997;11(3):275-80.

29. Van Gelder IC, Groenveld HF, Crijns HJ et al; RACE II Investigators. Lenient versus strict rate control in patients with atrial fibrillation. N Engl J Med. 2010;362(15):1363-73.

30. Gillinov AM, Bagiella E, Moskowitz AJ et al; CTSN. Rate Control versus Rhythm Control for Atrial Fibrillation after Cardiac Surgery. N Engl J Med. 2016;374(20):1911-21. 


\section{FIGURE 1. Flow chart of patients included and analyses performed; when considering $115 \mathrm{bpm}(\mathrm{A})$, or $130 \mathrm{bpm}(\mathrm{B})$ as threshold.}

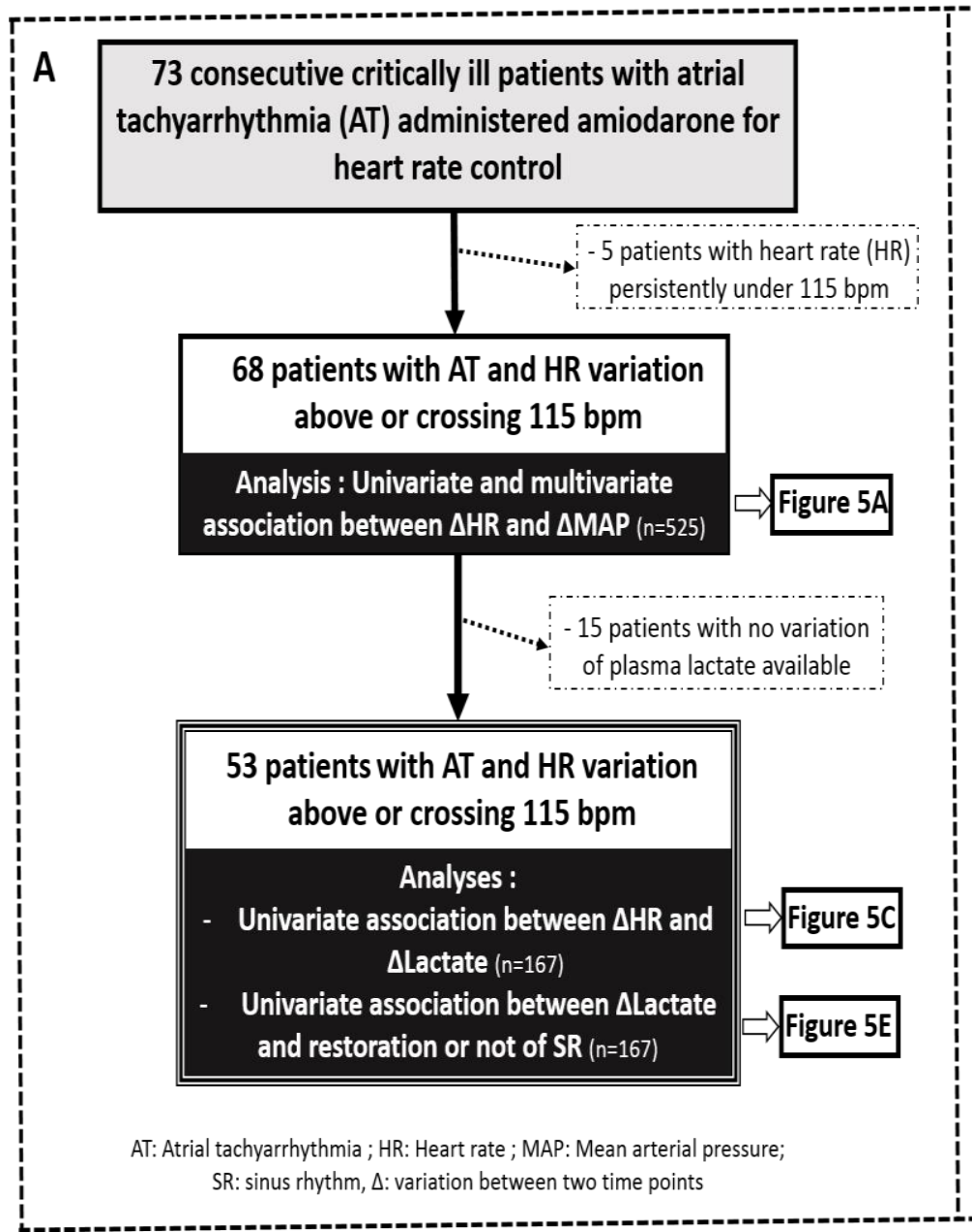

B
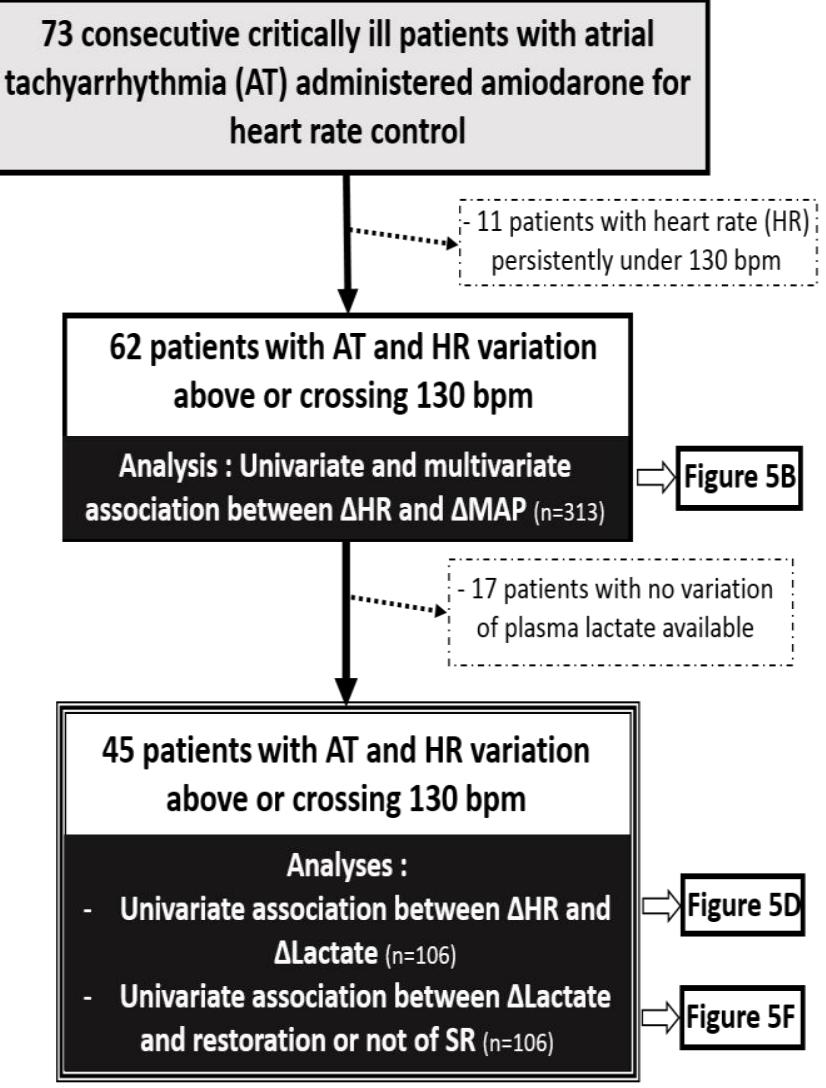

AT: Atrial tachyarrhythmia ; HR: Heart rate ; MAP: Mean arterial pressure; $S R$ : sinus rhythm, $\Delta$ : variation between two time points 
FIGURE 2. Representation of HR (bpm), MAP $(\mathrm{mmHg})$, and plasma lactate $(\mathrm{mmo} / \mathrm{l})$ collected over time (days) in the 73 studied patients with AT treated by amiodarone in ICU (arrow representing time of first dosing). Each gray-scale line linking the different circles represents a single patient.

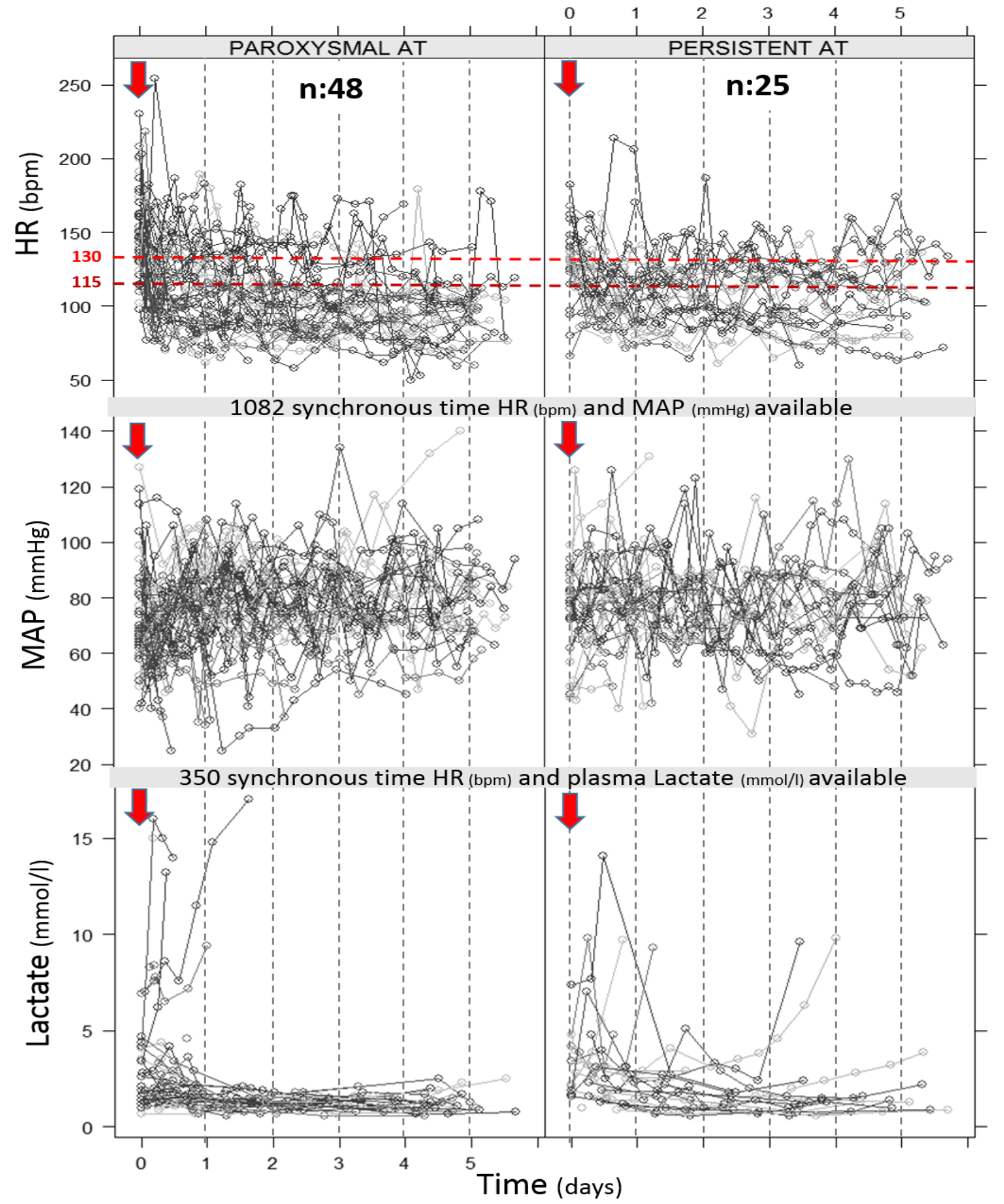


Figure 3. HR (bpm) in paroxysmal and persistent AT groups, represented as median and interquartile range (A). HR (bpm), MAP $(\mathrm{mmHg})$ and plasma lactate (mmol/l) in paroxysmal and persistent AT groups, represented as proportion of $\mathrm{HR}>130 \mathrm{bpm}(\mathrm{B}), \mathrm{MAP}<65 \mathrm{mmHg}(\mathrm{C})$ and plasma lactate $>2.2 \mathrm{mmol} / \mathrm{L}$ (D). Statistics were performed by Mann-Whitney or Chi-2 tests, as appropriate.

A
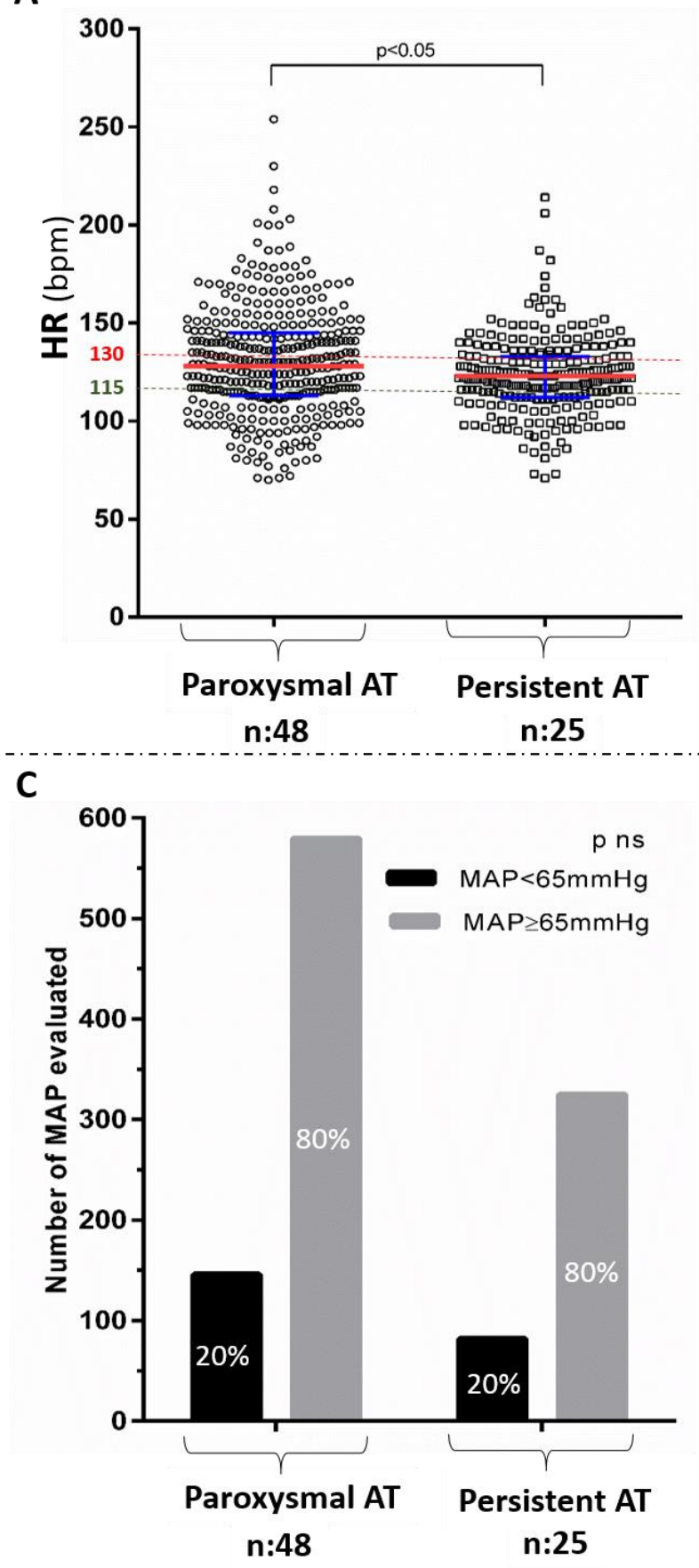

B

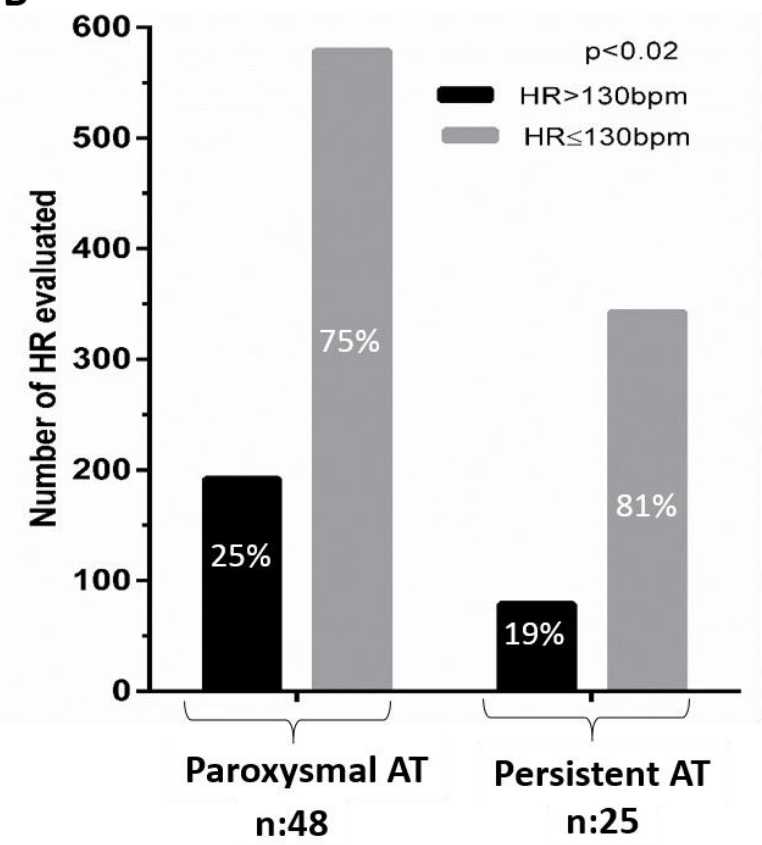

D

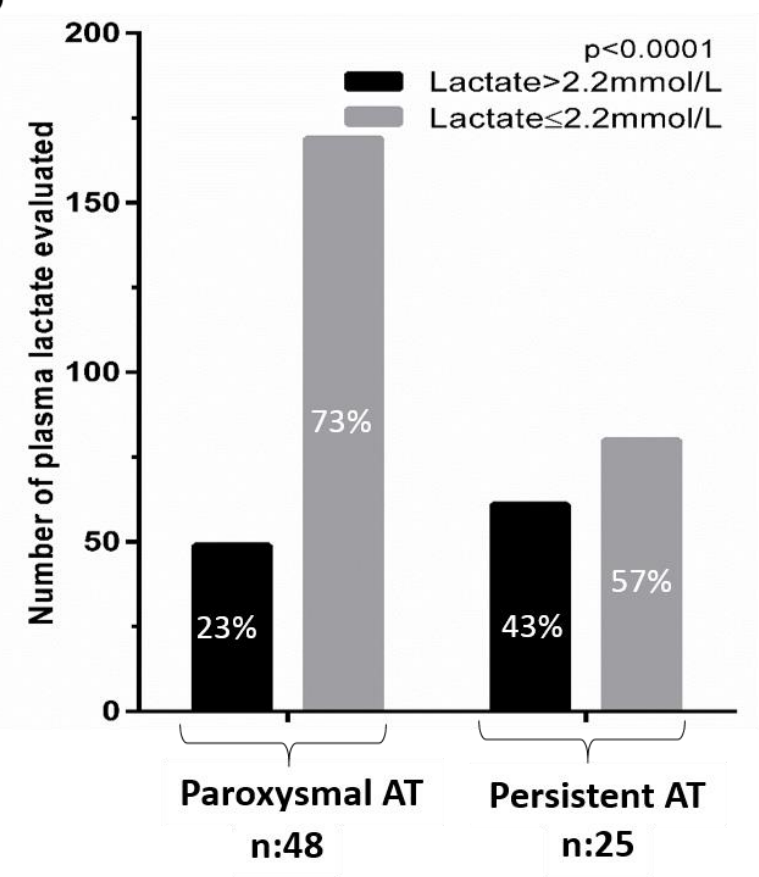


FIGURE 4. Correlation between variation in heart rate $(\Delta \mathrm{HR}$, bpm) and variation in simulated pharmacodynamically (PD) active amiodarone dose (mg).

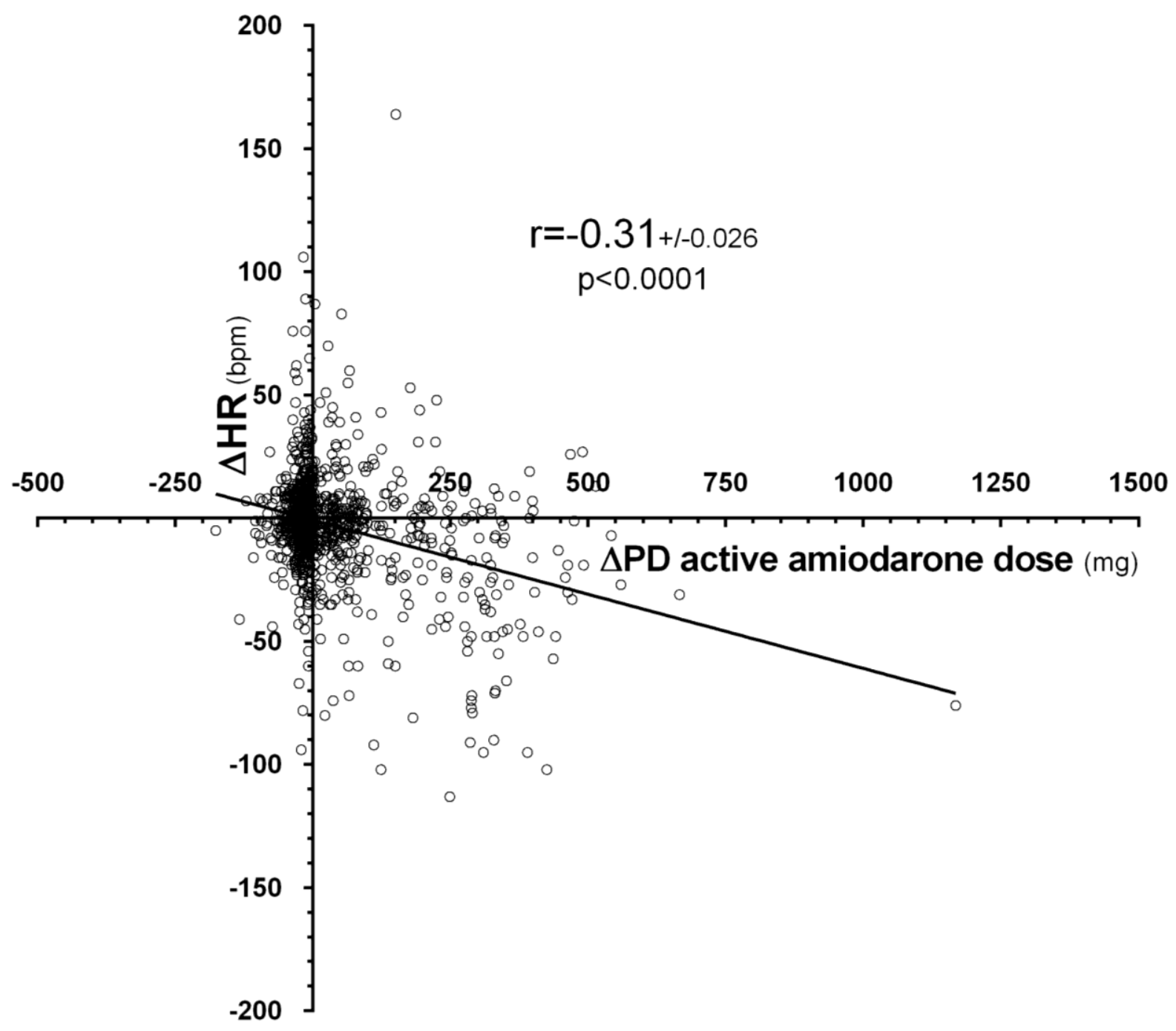


FIGURE 5. Correlation between variations of heart rate $(\Delta \mathrm{HR}, \mathrm{bpm})$ and mean arterial pressure $(\triangle M A P, m m H g$ ) when considering $115 \mathrm{bpm}(\mathrm{A})$ or $130 \mathrm{bpm}(B)$ as thresholds. Correlation between concomitant variations of heart rate $(\Delta \mathrm{HR}, \mathrm{bpm})$ and plasma lactate $(\Delta$ Lactate, $\mathrm{mmol} / \mathrm{l})$ when considering $115 \mathrm{bpm}(C)$ or $130 \mathrm{bpm}(D)$ as thresholds. Variation of plasma lactate $(\Delta$ Lactate, $\mathrm{mmol} / \mathrm{l})$ as a function of restoration of sinus rhythm ( $\mathrm{SR}$ restoration) or not (No), when considering $115 \mathrm{bpm}$ $(E)$ or $130 \mathrm{bpm}(\mathrm{F})$ as thresholds.
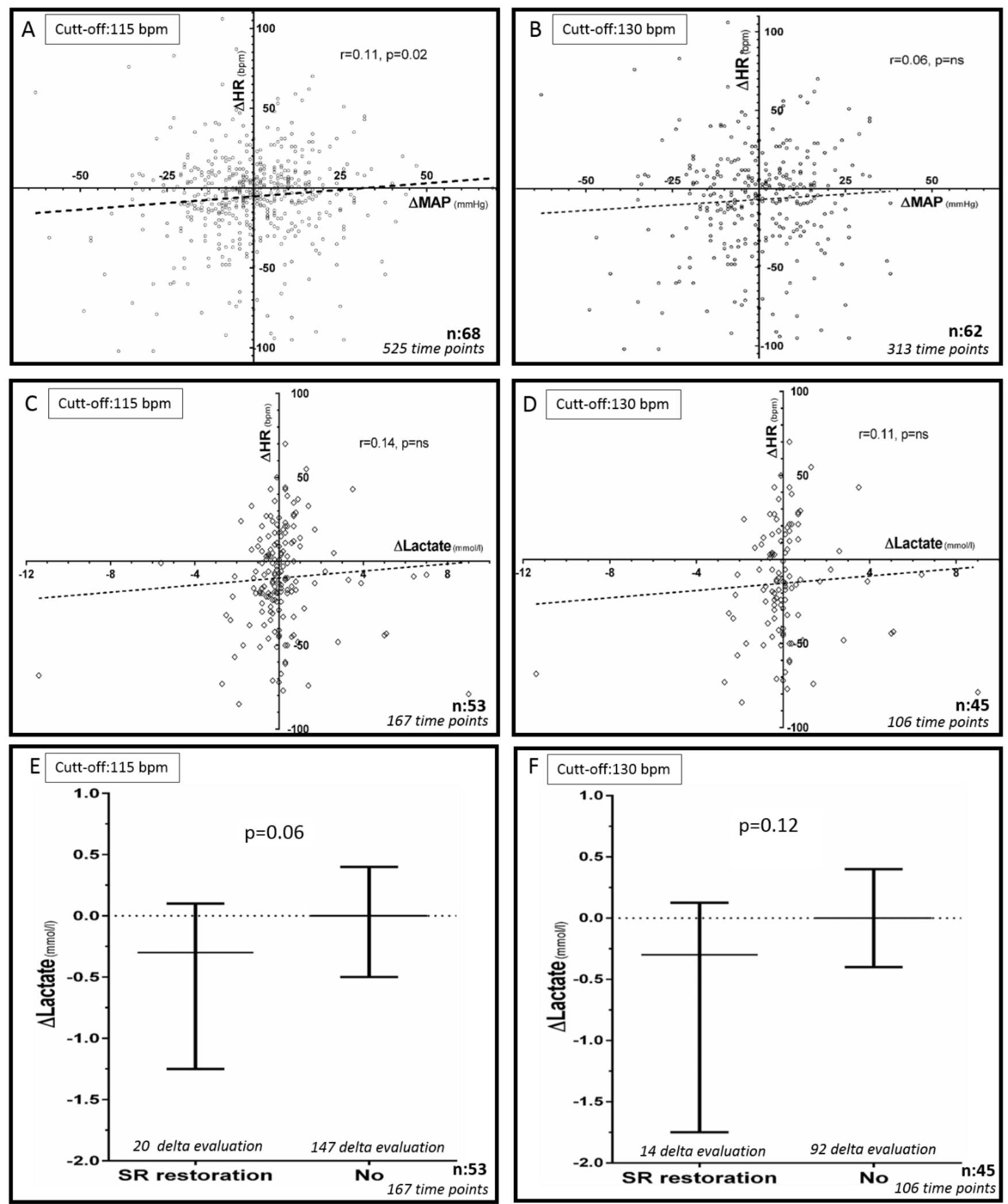
Table 1. Heart rate, rhythm and hemodynamic data of the 73 patients

\begin{tabular}{|c|c|}
\hline Characteristic & Value \\
\hline \multicolumn{2}{|l|}{ Heart rate data } \\
\hline Total number of HR collected & 1193 \\
\hline Median time between consecutive HR collected, hours & $5.04(4.08-7.44)$ \\
\hline Median time between first and last HR collected, days & $4.85(2.2-5.09)$ \\
\hline Total number of HR collected $\geq 200 \mathrm{bpm} /$ Number of patients concerned & $10 / 5$ \\
\hline Total number of HR collected $\geq 150 \mathrm{bpm} /$ Number of patients concerned & $106 / 40$ \\
\hline Total number of HR collected $\geq 130 \mathrm{bpm} /$ Number of patients concerned & $289 / 62$ \\
\hline Total number of HR collected $\geq 115 \mathrm{bpm} /$ Number of patients concerned & $492 / 68$ \\
\hline Total number of HR collected $\leq 75 \mathrm{bpm} /$ Number of patients concerned & $85 / 26$ \\
\hline Total number of HR collected $\leq 60 \mathrm{bpm} /$ Number of patients concerned & $6 / 5$ \\
\hline \multicolumn{2}{|l|}{ Mean arterial Pressure data } \\
\hline Total number of MAP collected & 1138 \\
\hline Median time between consecutive MAP collected, hours & $5.52(4.08-7.68)$ \\
\hline Total number of synchronous MAP and HR collected & 1082 \\
\hline Proportion of patients with at least one MAP $\leq 65 \mathrm{mmHg}$ & $55(75 \%)$ \\
\hline \multicolumn{2}{|l|}{ Plasma lactate data } \\
\hline Total number of plasma lactate collected & 359 \\
\hline Median time between consecutive plasma lactate collected, hours & $12(7.92-23.76)$ \\
\hline Total number of synchronous plasma lactate and HR collected & 350 \\
\hline Proportion of patients with at least one plasma lactate $\geq 2.2 \mathrm{mmol} / \mathrm{l}$ & $37(51 \%)$ \\
\hline
\end{tabular}


Abbreviations: bpm, beat per minute; HR, Heart rate; MAP, Mean arterial pressure.

Statistics: Values are given as the median (interquartile range 25-75) or number. 
Table 2. Main Characteristics of the $\mathbf{7 3}$ patients studied

Characteristic

\section{Demographic status and comorbidities}

Age, year

Male sex

Body weight, kilogram

Diabetes/Hypertension

Ischemic heart disease

Previous history of cardiac insufficiency

Previous history of supra-ventricular tachyarrhythmia

Prior amiodarone treatment before ICU: Chronic/Sub-acute

Chronic obstructive pulmonary disease

Chronic renal insufficiency (Clearance $<60 \mathrm{ml} / \mathrm{min} / \mathrm{m}^{2}$ )

APACHEII/SAPSII at admission in ICU

ICU mortality

Bio-clinical values at first HR/MAP collection (first amiodarone dosing in ICU)

Mean arterial pressure $<65 \mathrm{mmHg} /$ Need for catecholamine

Body Temperature, $\left({ }^{\circ} \mathrm{Celsius}\right.$, eardrum)

Non-invasive/invasive mechanical ventilation

Cardiac systolic dysfunction (Ejection fraction<45\%)

Sepsis

Paroxysmal/persistent atrial tachyarrhythmia

Atrial fibrillation / Flutter / Other atrial tachyarrhythmias
Value

$75 \pm 13$

$41(56 \%)$

$71 \pm 16$

$17(23 \%) / 36(49 \%)$

$30(41 \%)$

$28(38 \%)$

$21(29 \%)$

$8(11 \%) / 13(18 \%)$

$18(25 \%)$

$17(23 \%)$

$27 \pm 8 / 61 \pm 19$

$38(52 \%)$

$28(38 \%) / 39(53 \%)$

$37.1(36.4-38)$

$8(11 \%) / 41(56 \%)$

$27(37 \%)$

$34(47 \%)$

$48(66 \%) / 25(34 \%)$

$63(86 \%) / 4(5 \%) / 6(8 \%)$ 
$\mathrm{P}_{\mathrm{a}} \mathrm{O}_{2}(\mathrm{mmHg})$

$87(70-104)$

Hemoglobin $(\mathrm{g} / \mathrm{dL})$

10.6(9.1-12.2)

Creatinine clearance $\left(\mathrm{ml} / \mathrm{min} / \mathrm{m}^{2}\right)$

Total bilirubin ( $\mathrm{mmol} / \mathrm{l})$

$15(9-28)$

Treatments administered during HR, MAP and plasma lactate data collection

Attempted/Successful electrical cardioversion

$9(12 \%) / 4(5 \%)$

At least one amiodarone IV dose / oral dose

14(19\%) / 69(95\%)

Median amiodarone dose (IV route), $m g /$ dose

$300(150-300)$

Median amiodarone dose (oral), $\mathrm{mg} /$ dose

$400(200-1200)$

Other anti-arrhythmic (digoxin, beta-blocker, verapamil)

$2(3 \%), 1(1 \%), 1(1 \%)$

Catecholamine ( $\beta$-agonist): dobutamine

$8(11 \%)$

Catecholamine ( $\alpha$-and $\beta$-agonist): epinephrine

$45(61 \%)$

Fluid loading

$51(70 \%)$

Renal replacement therapy/Diuretics

$18(25 \%) / 36(49 \%)$

Sedative drugs/Curare

$44(60 \%) / 20(27 \%)$

\section{Estimated amiodarone dose at each time point (HR collection)}

Median estimated pharmacodynamically active amiodarone dose (mg)

$426(281-713)$

Mean estimated pharmacodynamically active amiodarone dose (mg)

$516 \pm 361$

Min/Maximal estimated pharmacodynamically active amiodarone dose (mg)

$0 / 1893$

Abbreviations: APACHEII, Acute Physiology And Chronic Health Evaluation at intensive care unit admission; HR, heart rate; ICU, intensive care unit; MAP, mean arterial pressure; SAPSII, simplified acute physiology score at intensive care unit admission; IV, intravenous; mg, milligram 
Statistics: Values are given as the mean \pm standard deviation, median (IQ, interquartile range 25-75) or number (\%). 